\title{
Hot cross bun and bright middle cerebellar peduncle signs in cerebellar type multiple system atrophy
}

\author{
Soumya Cicilet, Farha Furruqh, Asthik Biswas, Babu Philip
}

Department of Radiology, St John's Medical College Hospital, Bangalore, Karnataka, India

Correspondence to Dr Asthik Biswas, asthikbiswas@gmail.com

Accepted 10 August 2017

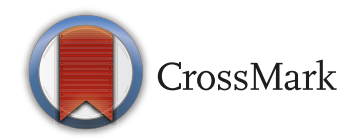

To cite: Cicilet $S$, Furrugh $F$, Biswas A, et al. BMJ Case Rep Published Online First: [please include Day Month Year]. doi:10.1136/bcr-2017220576

\section{DESCRIPTION}

A 52-year-old female patient presented with progressive gait unsteadiness for 6 months. Over the months, it has worsened to such an extent that she required support for walking. She also complained of frequent episodes of light-headedness on standing up from lying down or sitting down. She had no urge incontinence, urinary retention, increased frequency of micturition or constipation. She had no bradykinesia, rigidity, memory loss or features suggestive of dementia. There was no family history of similar complaints or dementia. On examination, she was found to have gait ataxia, nystagmus and intention tremors. The gait was broad based with sway towards left side. Her eye movements showed dysmetric saccades and jerky pursuit. She was also found to have postural hypotension. Her supine blood pressure was $170 / 90 \mathrm{~mm}$ $\mathrm{Hg}$ and her standing blood pressure was 140/70 mm $\mathrm{Hg}$. She had no resting tremor, rigidity or bradykinesia. Babinski's sign was negative. Deep tendon reflexes were normal. Her speech was normal. Her mental status examination was found to be within normal limits. A provisional clinical diagnosis of probable multiple system atrophy (MSA) was made. MRI brain study was performed, which showed cruciform hyperintense signal in the pons in T2 fluid-attenuated inversion recovery (FLAIR) images-hot cross bun sign (figure 1). T2 FLAIR hyperintensity of bilateral middle cerebellar

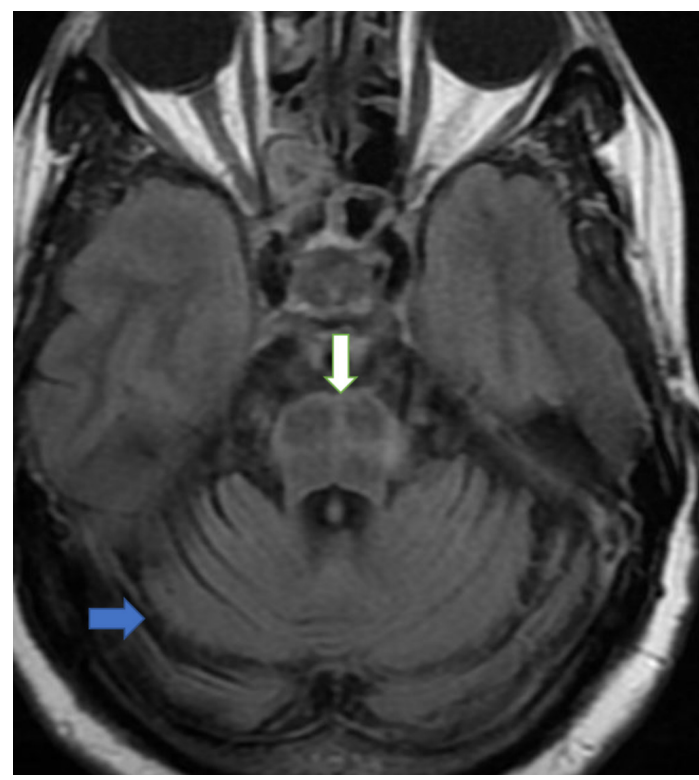

Figure 1 Axial T2 FLAIR image showing cruciform hyperintensity in pons and cerebellar atrophy.

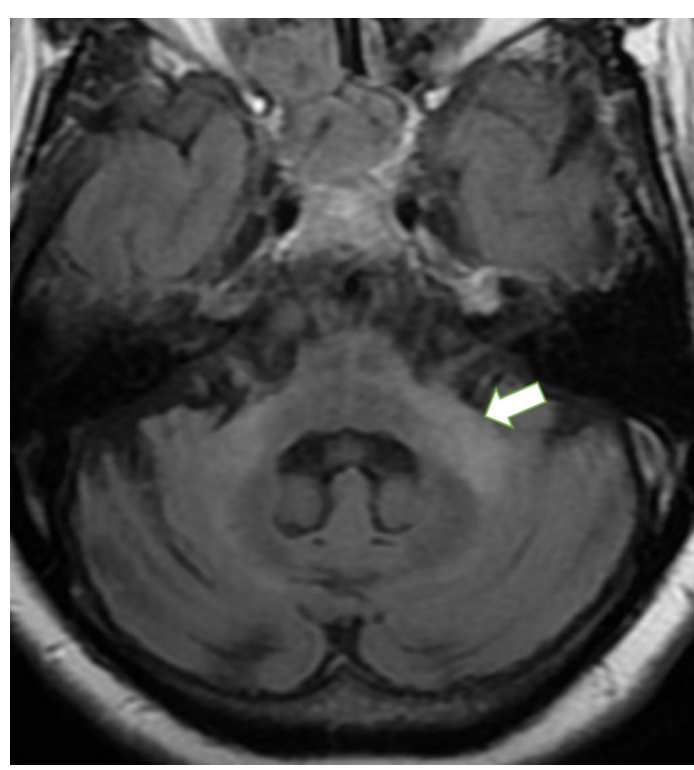

Figure 2 Axial T2 FLAIR image showing atrophy with high signal intensity in bilateral middle cerebellar peduncle. Cruciform hyperintensity in pons and cerebellar atrophy are also noted.

peduncles (MCPs) was also noted, which is known as bright MCP sign (figure 2). There was significant cerebellar atrophy (figures 1 and 2). The putamen showed no e/o atrophy or signal changes. There was no significant cerebral cortical atrophy. There was no postvoid residue on a urinary bladder ultrasound scan. Based on the history, clinical examination and imaging findings, a diagnosis of probable MSA cerebellar type (MSA-C) was made.

Multiple system atrophy is a neurodegenerative disorder that is classified under Parkinson plus syndromes with variable involvement of the basal ganglia, pontocerebellar region and the autonomic system. Striatonigral degeneration, olivopontocerebellar atrophy and Shy-Drager syndrome are now considered as part of MSA. ${ }^{1}$ The histopathological hallmark of MSA is accumulation of $\alpha$-synuclein within glial cytoplasmic inclusions. ${ }^{2}$ Based on clinical features, MSA is classified into MSA-P with predominant parkinsonism symptoms and MSA-C with predominant cerebellar and autonomic symptoms. ${ }^{3}$ Our patient presented with cerebellar ataxia and on examination was also found to have autonomic disturbance in the form of postural hypotension. MRI brain in patients with MSA-C show significant pontocerebellar atrophy with prominent fourth ventricle. ${ }^{1}$ Cruciform T2/T2 FLAIR hyperintensity is also noted in the axial sections of pons due to selective loss of myelinated transverse 
pontocerebellar fibres and neurons in the pontine raphe. This is known as the hot cross bun sign. High T2/T2 FLAIR signal intensity with volume loss is also noted in the middle cerebellar peduncles, which is known as the bright MCP sign. ${ }^{4}$ Our patient had both hot cross bun sign and bright MCP sign. The putamen in our patient showed no atrophy or T2 hypointense signal seen in MSA-P. ${ }^{3}$ The differential diagnosis of hot cross bun sign include MSA, spinocerebellar ataxia type 2 and type 3 (younger age of onset, associated with polyneuropathy, the myelinated transverse pontocerebellar fibres are preserved as compared with MSA-C) and Parkinsonism due to vasculitis (significantly higher load of subcortical white matter lesions). ${ }^{5}$ The bright MCP sign can also be seen in Wallerian degeneration post pontine infarct/ demyelination (gliosis in pons), fragile $\mathrm{X}$ tremor ataxia syndrome (involvement of splenium of corpus callosum and white matter lesions in cerebrum) and toluene abuse (periventricular white

\section{Learning points}

- Hot cross bun sign and bright middle cerebellar peduncles sign are seen in multiple system atrophy (MSA) cerebellar type.

- MRI is an invaluable tool in characterising MSA.

- Even though clinical symptoms and signs raise suspicion of neurodegenerative disorder, imaging helps in confirming the diagnosis. matter signal changes, thalamic hypointensity and cerebral atrophy). ${ }^{6}$ In the right clinical setting, a combination of hot cross bun sign and bright MCP sign should confirm diagnosis of probable MSA-C. The definite diagnosis can be made only on histopathological examination.?

Contributors SC: analysis and interpretation of the case. FF: conception and design. $A B$ : acquisition of images and clinical data. BP: proof reading, verification and final approval.

Competing interests None declared.

Patient consent Obtained.

Provenance and peer review Not commissioned; externally peer reviewed.

(c) BMJ Publishing Group Ltd (unless otherwise stated in the text of the article) 2017. All rights reserved. No commercial use is permitted unless otherwise expressly granted.

\section{REFERENCES}

1 Shrivastava A. The hot cross bun sign. Radiology 2007;245:606-7.

2 Dickson DW. Parkinson's disease and parkinsonism: neuropathology. Cold Spring Harb Perspect Med 2012;2:a009258.

3 Bhattacharya K, Saadia D, Eisenkraft B, et al. Brain magnetic resonance imaging in multiple-system atrophy and Parkinson disease: a diagnostic algorithm. Arch Neurol 2002;59:835-42.

4 Vijayan J, Sinha S, Ravishankar S, et al. MR imaging in multiple system atrophy: its role in 'splitting' parkinsonism. Ann Indian Acad Neurol 2008;11:257.

5 Soares-Fernandes JP, Ribeiro M, Machado A. 'Hot cross bun' sign in variant CreutzfeldtJakob disease. AJNR Am J Neuroradiol 2009;30:e37.

6 Morales H, Tomsick T. Middle cerebellar peduncles: Magnetic resonance imaging and pathophysiologic correlate. World J Radiol 2015;7:438-47.

7 Wenning GK, Colosimo C, Geser F, et al. Multiple system atrophy. Lancet Neurol 2004;3:93-103.

Copyright 2017 BMJ Publishing Group. All rights reserved. For permission to reuse any of this content visit http://group.bmj.com/group/rights-licensing/permissions.

BMJ Case Report Fellows may re-use this article for personal use and teaching without any further permission.

Become a Fellow of BMJ Case Reports today and you can:

- Submit as many cases as you like

- Enjoy fast sympathetic peer review and rapid publication of accepted articles

- Access all the published articles

- Re-use any of the published material for personal use and teaching without further permission

For information on Institutional Fellowships contact consortiasales@bmjgroup.com

Visit casereports.bmj.com for more articles like this and to become a Fellow 